\title{
Antropologia da civilização: um estudo da tradução para o inglês de termos simples, expressões fixas e semifixas recorrentes em duas obras de Darcy Ribeiro
}

\author{
Talita Serpa* \\ Diva Cardoso de Camargo ${ }^{\dagger}$
}

\begin{abstract}
The main purpose of this article is to investigate the most frequent simple terms as well as fixed and semi-fixed expressions in Social Anthropology of Civilization subarea in Portuguese and their corresponding terms in English, found in two works written by the anthropologist Darcy Ribeiro. The methodology used is that of Corpus-Based Translation Studies (BAKER, 1995, 1996, 1997; CAMARGO, 2005, 2007), Corpus Linguistics (Berber SaRdinHA, 2004) and Terminology (BARROS, 2004; KRIEGER \&FINATTO, 2004). Results show that there are similarities and differences among the use of the terms in the main subcorpora composed of source and target texts and in the comparable corpora in Portuguese and in English. This data indicate that terms and expressions are not univocal in the anthropological language due to the differences in the conceptualization of the same referents by different specialists in the area.
\end{abstract}

Keywords: Corpus-Based Translation Studies; Corpus Linguistic; Social Anthropology of Civilization.

Resumo: Neste estudo, foram selecionados os termos simples e as expressões fixas e semifixas mais frequentes da subárea de Antropologia da Civilização em português e seus correspondentes em inglês, extraídos de duas obras de autoria do antropólogo Darcy Ribeiro e das respectivas traduções para o inglês. A metodologia utilizada

\footnotetext{
* Mestranda pelo Programa de Pós-graduação em Estudos Linguísticos da Universidade Estadual Paulista - Câmpus de São J osé do Rio Preto. Email: talitasrp82@gmail.com.

† Professora adjunta do Departamento de Letras Modernas da Universidade Estadual Paulista - Câmpus São J osé do Rio Preto. Email: diva@ibilce.unesp.br.
} 
fundamentou-se nos Estudos da Tradução Baseados em Corpus (BAKER 1993, 1995, 1996; CAMARGO 2005, 2007), na Linguística de Corpus (Berber SARDINHA 2000, 2004; TOGNINI-BONELLI 2001) e na Terminologia (BARROS 2004; KRIEGER\&FINATTO 2004). Notouse que ocorrem semelhanças e diferenças de uso entre os termos dos subcorpora de estudo de textos, fonte e meta e dos corpora comparáveis em português e em inglês. Esses dados apontariam que os termos e as expressões não apresentam univocidade dentro dessa linguagem de especialidade, devido às diferenças de conceituação de um mesmo referente pelos especialistas da área.

Palavras-chave: Estudos da tradução baseados em corpus; Linguística de corpus; Antropologia da civilização. 
Serpa, T. \& Camargo, D. C. - Antropologia da civilização: um estudo da tradução para o inglês de termos simples, expressões fixas e semifixas recorrentes em duas obras de Darcy Ribeiro

\section{Introdução}

O desenvolvimento da pesquisa antropológica no Brasil ganhou forças a partir da criação do curso de Ciências Sociais pela Universidade de São Paulo (USP), na década de 1930. Até então, a pesquisa realizada no país fundamentava-se nas investigações das Escolas Francesa e Inglesa e tinha por principal material os relatos históricos dos grupos colonizadores, recorrendo ao eurocentrismo para proporcionar conhecimentos capazes de domesticar culturas adversas. Na contramão das perspectivas analíticas preconcebidas e importadas, o antropólogo, sociólogo, educador e político, Darcy Ribeiro, propôs a elaboração de uma subárea que se concentrasse na construção de uma avaliação das condições de promoção do processo civilizatório deste país, livre da ação teórica precedente, criando assim uma série de seis livros intitulada Antropologia da Civilização.

A esse respeito, RIBEIRO (1995) enfatiza que:

(...) nos faltava uma teoria geral, cuja luz nos tornasse explicáveis em seus próprios termos, fundida em nossa experiência histórica. As teorizações oriundas de outros contextos eram todas elas eurocêntricas demais e, por isso mesmo, impotentes para nos fazer inteligíveis. Nosso passado, não tendo sido o alheio, nosso presente não era necessariamente o passado deles, nem nosso futuro um futuro comum (RIBEIRO 1995: 13).

Diante de uma abordagem que valoriza a formação sociopolítica cultural da maior nação latino-americana, a tradução, na direção português $\rightarrow$ inglês, dessa nova teorização faz-se necessária, com o objetivo de proporcionar a divulgação dos trabalhos de Ribeiro em nível internacional, elevando a categoria da produção científica de antropólogos brasileiros fora do país. 
Serpa, T. \& Camargo, D. C. - Antropologia da civilização: um estudo da tradução para o inglês de termos simples, expressões fixas e semifixas recorrentes em duas obras de Darcy Ribeiro

No entanto, investigações sobre o uso de termos encontrados nas obras 0 processo civilizatório (1968) e O povo brasileiro: formação e sentido do Brasil (1995), assim como sobre o processo tradutório que os envolve são inexistentes, evidenciando a necessidade de observar, a partir desses textos de especialidade, as opções adotadas para a tradução dos termos simples, expressões fixas e semifixas.

Pesquisas voltadas para os Estudos da Tradução Baseados em Corpus (BAKer 1993, 1995, 1996; CAMARGo 2005, 2007) e para a Linguística de Corpus (Berber SARDinha 2000, 2004) salientam a importância do estudo da linguagem por meio de exemplos de uso real da língua. BAKER (1996) também aponta que a análise de corpus proporciona o reconhecimento de traços considerados como característicos e distintivos da linguagem da tradução.

Também foram observadas as tendências linguísticas apresentadas por Betty J. Meggers e Gregory Rabassa nas respectivas traduções The Civilizational Process (1968) e The Brazilian People: formation and meaning of Brazil (2000), a fim de verificar as escolhas lexicais por eles adotadas e investigar a ocorrência ou não de padronizações terminológicas nas subáreas das Ciências Sociais, examinando as opções de tradução utilizadas para termos recorrentes nos dois pares de obras.

\section{Fundamentação teórica}

Este trabalho baseou-se no arcabouço teórico-metodológico lançado por BAKER (1993, 1995, 1996, 2000). Segundo essa pesquisadora:

[...] textos traduzidos registram eventos comunicativos genuínos e como tais não são nem inferiores nem superiores aos outros eventos comunicativos em qualquer língua. Entretanto, eles são diferentes, e a 
Serpa, T. \& Camargo, D. C. - Antropologia da civilização: um estudo da tradução para o inglês de termos simples, expressões fixas e semifixas recorrentes em duas obras de Darcy Ribeiro

natureza dessa diferença precisa ser explorada e registrada ${ }^{1}$ (BAKER 1993: 234).

Para desenvolver sua proposta, a teórica fundamentou-se nos Estudos Descritivos da Tradução, com base nos trabalhos de Even-Zohar (1978) e, principalmente, nos de TOURY (1978). A autora também se apoiou nas investigações de SINCLAIR (1991), no tocante ao aporte teórico da Linguística de Corpus e ao uso de corpora eletrônicos e ferramentas computacionais para a realização de pesquisas nos textos meta (TMs).

BAKER (1995) apresenta sua concepção de corpus na qual explicita a preferência pela análise por meio de computador:

[...] corpus é um conjunto de textos naturais (em oposição a exemplos/ sentenças), organizados em formato eletrônico, passíveis de serem analisados, preferencialmente, em forma automática ou semiautomática (sic) (em vez de manualmente) ${ }^{2}$ (BAKER 1995: 226).

Em associação a essas teorias, o presente trabalho também fez uso de pressupostos da Terminologia. O tradutor que se dedica a uma área de especialidade inevitavelmente utiliza em seu trabalho termos específicos e a linguagem adequada ao campo escolhido. Adota dicionários e glossários especializados com o objetivo de produzir um texto na língua meta (LM) adequado aos padrões e à tipologia da área de especialidade. Dessa forma, a Tradução e a Terminologia se entrecruzam favorecendo a prática tradutória.

Sobre a colaboração entre a tradução e os estudos terminológicos, BARROS (2004) comenta que:

A cooperação entre tradutores e terminólogos, ou mais particularmente o trabalho dos tradutores como terminólogos, pode

\footnotetext{
${ }^{1}$ Translated texts record genuine communicative events and as such are neither inferior nor superior toother communicative events in any language. They are however different, and the nature of this differenceneeds to be explored and recorded.

${ }^{2}$ Corpus mean[s]any collection of running texts (as opposed to examples/sentences), held in electronic form and analysable automatically or semi-automatically (rather than manually).
} 
Serpa, T. \& Camargo, D. C. - Antropologia da civilização: um estudo da tradução para o inglês de termos simples, expressões fixas e semifixas recorrentes em duas obras de Darcy Ribeiro

ser testemunhado por inúmeras obras terminográficas bilíngues ou multilingues, elaboradas em épocas diferentes, tanto no Ocidente quanto no Oriente. Atualmente, a importância da participação dos tradutores na elaboração desse tipo de obra é incontestável. Com efeito, diversos bancos de dados especializados de alcance mundial têm no tradutor um grande colaborador (BARROS 2004: 72).

A Terminologia fornece, pois, o material necessário à Tradução para o acesso rápido aos termos apropriados da área. Em decorrência, houve um aumento dos trabalhos em Tradução e Terminologia que fornecem termos adequados para consultas das áreas de especialidade a serem traduzidas. Muitas vezes, o tradutor atua como terminólogo "ao criar neologismos ou mesmo paráfrases do termo para dar conta das equivalências semânticas" (KRIEGER \& FINATTO 2004: 72).

BARROS (2004) acrescenta que cada povo recorta a realidade objetiva de maneira distinta e que as formulações conceituais das representações sociais são designadas por unidades lexicais que, consideradas como signos de domínios específicos da atividade da comunidade sociocultural, podem ser afirmadas como unidades terminológicas. A teórica debruça-se sobre a questão antropológica da descrição do sistema cultural de um povo e afirma haver a necessidade da construção de um conjunto terminológico específico a essa área. Verifica-se, portanto, que cada antropólogo, e ousaríamos afirmar que cada cientista social, delimita seu campo de estudo e procura conhecer as nomeações dos seus objetos de análise. Dessa forma, pode-se dizer que nas Ciências Sociais, além de uma terminologia científica própria a constituição de conceitos acadêmicos, existe também a necessidade de se considerar a nomenclatura dos elementos sociais investigados. Tem-se, por conseguinte, que as subáreas das Ciências Sociais apresentam um vocabulário especializado com a criação de conceitos teóricos que assumem características próprias dentro da obra de cada pesquisador. 
Serpa, T. \& Camargo, D. C. - Antropologia da civilização: um estudo da tradução para o inglês de termos simples, expressões fixas e semifixas recorrentes em duas obras de Darcy Ribeiro

Neste sentido, PathaK (1998) acrescenta que a formulação terminológica no campo das Ciências Sociais possui determinados aspectos condicionantes que o diferem das demais áreas de especialidade. Esse campo de investigação apresenta diversos termos que podem designar um mesmo conceito, como, por exemplo, o termo simples "nacionalização" e a expressão "área sob domínio governamental". Pode-se também salientar que um mesmo termo pode designar diferentes conceitos, no caso de "socialização" que se aplica às subáreas de Antropologia, Economia e Sociologia em diferentes contextos. Outros fatores observados são que os cientistas sociais associam conceitos distintos a um único termo; os conceitos são geralmente expressos por palavras de uso cotidiano; e em Ciências Sociais os termos não são formulados em linguagem simbólica.

Contudo, a maioria dos estudiosos dedica-se a fenômenos socioculturais específicos e, com isso, os fatos e os elementos da sociedade sob pesquisa tornam-se parte da Terminologia daquele autor. No caso das pesquisas realizadas no Brasil, pode-se considerar esses fatores como brasileirismos, os quais, de acordo com CoelHo (2003), podem ser considerados como índices linguísticos da identidade do povo brasileiro.

Para FAULSTICH (2004), algumas destas entidades linguístico-culturais assumem um quadro conceitual que é mais de natureza terminológica do que de linguagem comum, compondo os chamados brasileirismos terminológicos. Admite-se, com isso, que estas unidades lexicais constituem um caráter funcional em contextos científicos específicos. A teórica define os brasileirismos terminológicos como "palavras, locuções e outra estrutura sintagmática criada e formada no Brasil, que tenha significado autônomo e esteja encerrado num conceito de especialidade, que possibilite reconhecer a área a que pertence" (FAULSTICH 2004).

Segundo Michael Henry Heim\&Andrzej W. Tymowski, pesquisadores do American Council of Learned Societies, o processo tradutório de tal repertório 
Serpa, T. \& Camargo, D. C. - Antropologia da civilização: um estudo da tradução para o inglês de termos simples, expressões fixas e semifixas recorrentes em duas obras de Darcy Ribeiro

terminológico precisa seguir algumas diretrizes metodológicas, visto que os textos das áreas antropológica, sociológica etc. são distintos dos demais textos científicos por não poderem ser generalizados e estarem submetidos a contextos sociais, políticos e culturais distintos, de acordo com o país e as tradições e os costumes que o constituem.

Embora afirmem que essa submissão a fatores sociais específicos de determinadas culturas gere inconsistência terminológica, HEIM\&TYMOWSKI (2006) não deixam de observar que:

Um termo-chave que ocorre mais de uma vez pode ser traduzido pela mesma palavra sempre, mas o tradutor precisa primeiramente determinar se 0 significado é de fato o mesmo. Se não for, o tradutor pode escolher outra palavra, mas a decisão deve ser consciente. Para estabelecer consistência à tradução, o editor pode sugerir que os tradutores elaborem um glossário de termos-chave quando trabalham com um texto específico ${ }^{3}$ (HEIM \& TYMOWSKI 2006: 10).

Os cientistas sociais, ao introduzirem novos conceitos, geralmente atuam para que as palavras ou expressões empregadas sejam aceitas pela comunidade científica e se universalizem dentro desse público, passando a constituir termos. Bons exemplos disso são a ninguendade e a transfiguração étnica (1995) de DARCY RIBEIRO. Os conceitos que transmitem são, em geral, culturalmente determinados, mas a opção por termos técnicos é um aspecto dessas ciências e, por isso, os tradutores precisam estar atentos no momento de vertê-los para as LMs.

Embora não seja possível generalizar, os dois principais procedimentos utilizados pela maioria dos tradutores, de acordo com Heim\&Tymowski, são: (1) empréstimo da língua original e (2) tradução literal para o termo. Ambos causam um estranhamento inicial no leitor alvo, pois ou estão em língua

${ }^{3}[. .$.$] a key term that occurs more than once should be translated by the same word$ each time, but the translator must first determine whether the meaning is in fact the same. If it is not, the translator may choose another word, but the decision must be a conscious one. To foster consistency, the editor can suggest that translators create a personal glossary of key terms as they work through a text. 
Serpa, T. \& Camargo, D. C. - Antropologia da civilização: um estudo da tradução para o inglês de termos simples, expressões fixas e semifixas recorrentes em duas obras de Darcy Ribeiro

estrangeira ou forçam o original da LM a uma forma que não lhe é natural. No entanto, frequentemente, as línguas se adaptam e absorvem os "estrangeirismos" e as "literalidades".

É importante que o tradutor, que irá verter um texto científico, esteja familiarizado com o tipo de redação e, também, com os termos mais adequados a cada subárea das Ciências Sociais. Essa é uma das condições apontadas pelos autores por facilitar que os textos sejam publicados de acordo com padrões internacionais. Tanto os tradutores e pesquisadores da área quanto os estudantes de tradução seriam diretamente beneficiados com os resultados de trabalhos voltados para esses propósitos.

No âmbito de obras de cunho cultural, político e social, Michaela Wolf, em seu artigo Translation as a Process of Power: aspects of cultural anthropology in translation (1995), salienta que é nestes textos, assim como em textos literários, que as assimetrias de transferência cultural tornam-se mais visíveis; isso porque a questão de poder entre as sociedades dominantes e dominadas está nitidamente expressa nas escolhas linguísticas de autor e tradutor.

Tendo por base tais questões, apresenta-se uma investigação sobre a tradução de termos simples, expressões fixas e semifixas da subárea de Antropologia da Civilização com vistas ao seu uso por tradutores e especialistas em Ciências Sociais.

De acordo com BARROS (2004), termos caracterizam-se por designarem conceitos específicos de um domínio de especialidade. Por sua vez, BAKER (1992) salienta que as expressões fixas tratam-se de expressões consagradas, referentes a determinado tipo de texto e que permitem pouca ou nenhuma variação. No caso das expressões semifixas, CAMARGo (2005) aponta que estas apresentam maior variação e carregam consigo todo um contexto, podendo ser consideradas específicas de uma determinada língua de especialidade. 
Serpa, T. \& Camargo, D. C. - Antropologia da civilização: um estudo da tradução para o inglês de termos simples, expressões fixas e semifixas recorrentes em duas obras de Darcy Ribeiro

Para o levantamento foram utilizadas as ferramentas WordList, Keywords Concord do software WordSmith Tools, as quais facilitam a compilação dos termos e de seus contextos.

\section{Material e Método}

Para esta investigação, foram compilados os seguintes corpora: 1) um subcorpus principal paralelo de Antropologia da Civilização, constituído pela obra científica 0 processo civilizatório (OPC), de autoria de Darcy Ribeiro, publicada originalmente em português no ano de 1968 (total de itens: 63.159), e a respectiva tradução para o inglês, realizada por Betty J. Meggers sob o título The Civilizational Process, publicada em 1968 (total de itens: 53.464); 2) um subcorpus principal paralelo constituído pela obra 0 povo brasileiro: a formação e o sentido do Brasil(OPB), de autoria de Darcy Ribeiro, publicada originalmente em português, no ano de 1995 (total de itens: 115.474), e a respectiva tradução para o inglês, realizada por Gregory Rabassa, sob o título The Brazilian People: formation and meaning of Brazil, publicada em 2000 (total de itens: 139.858); 3) um corpus comparável de controle, composto por 15 obras da mesma subárea escritas originalmente em português; 4) um corpus comparável de controle, composto por 15 obras da mesma subárea escritas originalmente em inglês.

As obras que compõem o corpus comparável em português representam publicações de pesquisas relacionadas à constituição do povo brasileiro, de autoria dos nossos mais importantes antropólogos, como por exemplo, Gilberto Freyre, Eduardo Viveiros de Castro, Marcio Goldman e Roberto DaMatta, publicadas entre as décadas de 1930 e 1990 do século XX. 
Serpa, T. \& Camargo, D. C. - Antropologia da civilização: um estudo da tradução para o inglês de termos simples, expressões fixas e semifixas recorrentes em duas obras de Darcy Ribeiro

Para a formação do corpus comparável em inglês foram utilizados textos clássicos da Antropologia Britânica e Americana, desenvolvidos por autores consagrados, como Bronislaw Malinowski, Radcliffe-Brown, Margaret Mead, Franz-Boas e Mary Douglas, e publicados entre os séculos XIX e XX. Cabe salientar que as obras destes autores constam da bibliografia utilizada para a composição das teorias revolucionárias de Darcy Ribeiro.

Também foram utilizados dois corpora de referência para a extração de palavras-chave. Em português, foi utilizado o corpus Lácio-Ref ${ }^{4}$, composto de textos em português brasileiro, escritos respeitando a norma culta. Para a extração de palavras-chave em inglês, empregou-se como corpus de referência o British National Corpus (BNC Sampler) ${ }^{5}$, composto por textos originalmente escritos em inglês.

\section{Análise e discussão dos resultados}

Para o levantamento de termos simples, expressões fixas e semifixas de Antropologia de Civilização foram selecionados os vocábulos mais representativos de base substantival e adjetival do subcorpus de estudo.

A análise da obra OPC foi realizada por meio das listas de frequência de palavras extraídas com o auxílio da ferramenta WordList. Apresentam-se, a seguir, as Tabelas 1 e 2 com as dez palavras mais frequentes nos textos fonte (TFs) e nos TMs.

\begin{tabular}{l|l|l|l}
\hline 1. Sociedades & 4. Revolução & 7. Trabalho & 10. Cultural \\
2. Povos & 5. Processo & 8. Evolução & \\
3. Social & 6. Desenvolvimento & 9. Poder & \\
\hline
\end{tabular}

${ }^{4} \mathrm{O}$ Lácio-Ref é um corpus aberto e de referência do português contemporâneo do Projeto Lácio-Web, composto por textos em português brasileiro.

${ }^{5} \mathrm{O}$ BNC Sampleré um subcorpus do British National Corpus, o qual contém amostras de língua falada e escrita, subdivididas para utilização em dois bancos de dados distintos. 
Serpa, T. \& Camargo, D. C. - Antropologia da civilização: um estudo da tradução para o inglês de termos simples, expressões fixas e semifixas recorrentes em duas obras de Darcy Ribeiro

\section{Tabela 1: Lista das dez palavras mais frequentes no subcorpus principal da obra OPC em português}

\begin{tabular}{l|l|l|l}
\hline 1. Social & 4. Process & 7. Civilizational & 10. Labor \\
2. Revolution & 5. Cultural & $\begin{array}{l}\text { 8. Development } \\
\text { 3. Societies }\end{array}$ & 6. System
\end{tabular}

Tabela 2: Lista das dez palavras mais frequentes no subcorpus principal da obra OPC em inglês

Das palavras presentes na Tabela 1, foram encontradas oito equivalentes na Tabela 2: "sociedade/s" $\rightarrow$ society/ies; "povo/s" $\rightarrow$ people/s; "social/is" $\rightarrow$ social/s; "revolução/ões" $\rightarrow$ revolution/s; "processo/s" $\rightarrow$ process/es; "desenvolvimento" $\rightarrow$ development/s; e "trabalho/s" $\rightarrow$ labor/s. As outras duas palavras que não constaram entre as dez primeiras ("evolução/ões" $\rightarrow$ evolution/s; "poder/es" $\rightarrow$ power/s) apareceram entre as cem palavras mais frequentes na lista de palavras do subcorpus dos TMs. Também foi possível notar que vocábulos de maior ocorrência, como por exemplo, "sociedade/s" (204) ${ }^{6}$, "povo/s" (203) e "social/ is" (182) fazem parte da linguagem geral das Ciências Sociais. A observação da frequência de tais itens lexicais na primeira obra da série Antropologia da Civilização permite reconhecer quais os principais assuntos abordados pelo autor, que trata dos processos de civilização dos países latino-americanos, considerando que a pesquisa foi desenvolvida com o objetivo de traçar um panorama arqueológico geral da fundação dos Estados Neolatinos na América. Dessa forma, uma vez presentes na lista de palavras mais frequentes e mais representativas do subcorpus, os termos foram mantidos na análise da subárea antropológica.

Com o auxílio da ferramenta Keywords foram geradas as listas de palavras-chave do subcorpus de TF, tomando para contraste o corpus de referência Lácio-Ref. Após este levantamento foram também observadas as palavras-chave a partir do TM, tendo como corpus de referência o BNC

\footnotetext{
${ }^{6}$ Os números entre parênteses correspondem à frequência em que os termos ocorreram no corpus principal paralelo.
} 
Serpa, T. \& Camargo, D. C. - Antropologia da civilização: um estudo da tradução para o inglês de termos simples, expressões fixas e semifixas recorrentes em duas obras de Darcy Ribeiro

Sampler. A seguir, apresentam-se as Tabelas 3 e 4 com as respectivas dez palavras-chave de maior índice:

\begin{tabular}{l|l|l|l}
\hline 1. Sociedades & 4. Revolução & 7. Desenvolvimento & 10. Impérios \\
2. Povos & 5. Processo & 8. Poder & \\
3. Social & 6. Sistema & 9. Produção & \\
\hline
\end{tabular}

Tabela 3: Lista das dez palavras-chave a partir do subcorpus principal da obra OPC em português

\begin{tabular}{l|l|l|l}
\hline 1. Socialism & 4. Subsistence & 7. Industrialization & 10. Collectivist \\
2. Socialist & 5. Feudalism & 8. Tribal & \\
3. Sectors & 6. Export & 9. Conquest & \\
\hline
\end{tabular}

Tabela 4: Lista das dez palavras-chave a partir do subcorpus principal da obra OPC em inglês

Para dar suporte à seleção de tais dados, realizou-se uma consulta a um corpus de apoio formado por dicionários das subáreas das Ciências Sociais, a saber: Antropologia, Ciência Política, Economia e Sociologia, com o objetivo de confirmar sua inclusão ou exclusão nas análises.

Da mesma forma, foram realizadas investigações semelhantes para 0 subcorpus da obra OPB. A seguir, apresentam-se as Tabelas 5 a 8 com as dez palavras mais frequentes e as dez palavras-chave dos TFs e dos TMs.

\begin{tabular}{l|l|l|l}
\hline 1. Indios & 4. Social & 7. Brasileiros & 10. Nacional \\
2. População & 5. Sociedade & 8. Mundo & \\
3. Trabalho & 6. Negros & 9. Gente & \\
\hline
\end{tabular}

Tabela 5: Lista das dez palavras mais frequentes no subcorpus principal da obra OPB em português

\begin{tabular}{l|l|l|l}
\hline 1. Indians & 4. Land & 7. World & 10. Work \\
2. Peoples & 5. Population & 8. Order & \\
3. Brazilian & 6. Social & 9. Society & \\
\hline
\end{tabular}

Tabela 6: Lista das dez palavras mais frequentes no subcorpus principal da obra OPB em inglês

\begin{tabular}{l|l|l|l}
\hline 1. Indios & 4. Sociedade & 7. Gente & 10. Escravos \\
2. População & 5. Negros & 8. Povo & \\
3. Terra & 6. Brasileiros & 9. Economia & \\
\hline
\end{tabular}

Tabela 7: Lista das dez palavras-chave a partir do subcorpus principal da obra OPB em português

\begin{tabular}{l|l|l|l}
\hline 1. Indians & 4. Population & $\begin{array}{l}\text { 7. World } \\
\text { 8. Order }\end{array}$ & 10. Slaves \\
2. People & 5. Land & 8. & \\
\hline
\end{tabular}


Serpa, T. \& Camargo, D. C. - Antropologia da civilização: um estudo da tradução para o inglês de termos simples, expressões fixas e semifixas recorrentes em duas obras de Darcy Ribeiro

\section{\begin{tabular}{l|l|l} 
3. Brazilian & 6. Social & 9. Society
\end{tabular} \\ Tabela 8: Lista das dez palavras-chave a partir do subcorpus principal da obra OPB em inglês}

Notou-se que as listas de palavras-chave destacaram a representatividade do subcorpus, uma vez que apresentavam as palavras de maior chavicidade a partir de um corpus de referência com mais de um milhão de palavras, o que indica uso frequente de palavras apontadas como fortes candidatas a termos na subárea de Antropologia da Civilização. Tal resultado mostra a validade de um levantamento de termos com a metodologia da Linguística de Corpus e da Terminologia, dado que auxiliou no refinamento das listas apresentadas neste trabalho, as quais poderão assessorar o tradutor ao lidar com textos específicos de Ciências Sociais. Os dados apontam uma diferença na tradução terminológica na subárea em análise, mostrando que os tradutores optaram por algumas escolhas léxicas distintas ao levarem a teoria de Darcy Ribeiro para o público alvo. No entanto, a maioria dos candidatos a termos observados apresentou traduções semelhantes em ambas as obras em língua inglesa, como, por exemplo, em: "desenvolvimento" $\rightarrow$ development; "povo/s" $\rightarrow$ people/s; "população/ões" $\rightarrow$ population/s; "processo/s" $\rightarrow$ process/ es; e "sociedade/ s" $\rightarrow$ society/ ies.

Dessa maneira foi possível reconhecer pelo menos quatro possíveis subdivisões para a composição terminológica em Antropologia da Civilização: (1) termos relacionados aos atores de mudança social, como, por exemplo, escravos e indígenas; (2) grupos ou padrões de coletividade, no caso de populações; (3) processos e atividades sociais, como a abolição e o feudalismo; (4) locais de interação sociocultural e política, como latifúndios e fazendas.

As palavras-chave selecionadas a partir dos subcorpora principais dos TFs foram comparadas às palavras-chave extraídas a partir dos TMs. A investigação dos termos mais frequentes permitiu constatar que, em grande 
Serpa, T. \& Camargo, D. C. - Antropologia da civilização: um estudo da tradução para o inglês de termos simples, expressões fixas e semifixas recorrentes em duas obras de Darcy Ribeiro

parte, as palavras-chave dos subcorpora principais em língua inglesa coincidiam com as palavras-chave de língua portuguesa em ambas as subáreas. Tal ocorrência facilitou a análise das possíveis traduções para os referidos termos.

Com base nesses dados, apresentam-se, a seguir, as Tabelas 9 e 10 com os dez primeiros candidatos a termos simples mais frequentes nos TFs e as respectivas traduções, extraídos dos subcorpora paralelos:

\begin{tabular}{ll|ll|ll|l}
\hline \multicolumn{2}{c|}{ TF } & \multicolumn{3}{c}{ TM } \\
\hline 1. Sociedades & 6. Sistema & 1. & Societies & 6. System \\
2. Povo & 7. Desenvolvimento & 2. & People & 7. Development \\
3. Social & 8. Poder & 3. Social & 8. Power \\
4. Revolução & 9. Produção & 4. Revolution & 9. Production \\
5. Processo & 10. Impérios & 5. Process & 10. Empires \\
\hline
\end{tabular}

Tabela 9: Dez candidatos a termos simples mais frequentes no TF da obra OPC e respectivas traduções no TM

\begin{tabular}{ll|ll|l|l}
\hline \multicolumn{4}{c|}{ TF } & \multicolumn{2}{c}{ TM } \\
\hline 1. & Indios & 6. & Brasileiros & 1. Indians & 6. Brazilians \\
2. População & 7. Gente & 2. Population & 7. People \\
3. Terra & 8. Povo & 3. Land & 8. People \\
4. Sociedade & 9. Economia & 4. Society & 9. Economy \\
5. Negros & 10. Escravos & 5. Blacks/ Negroes & 10. Slaves \\
\hline
\end{tabular}

Tabela 10: Dez candidatos a termos simples mais frequentes no TF da obra OPB e respectivas traduções no TM

Foi possível notar que o processo de análise dos termos mais frequentes das obras revela algumas recorrências de terminologia, o que demonstra que 0 autor desenvolveu um estudo em que as teorias foram sendo aprimoradas e reavaliadas a cada nova obra. Dessa forma, ao concluir a análise em Antropologia da Civilização com a publicação de 0 povo brasileiro, Ribeiro procurou sintetizar as descobertas acerca da constituição da civilização brasileira e demonstrar a evolução dos dados apresentados na obra precedente 0 processo civilizatório.

A partir das palavras-chave levantadas foi realizada a observação das linhas de concordância, dos agrupamentos lexicais (clusters) e dos colocados (collocates) com a utilização da ferramenta Concord. A seguir, apresentam- 
Serpa, T. \& Camargo, D. C. - Antropologia da civilização: um estudo da tradução para o inglês de termos simples, expressões fixas e semifixas recorrentes em duas obras de Darcy Ribeiro

se, nas Tabelas 11 e 12, cinco dos candidatos a termos mais frequentes em ambas as subáreas e as expressões por eles formadas ("sociedade/s", "economia/s", "desenvolvimento/s", "processo" e "sistema/s"):

\section{SOCIEDADE/ S}

Sociedades Humanas - Sociedades Subalternas - Sociedades Industriais Sociedades Capitalistas - Sociedades Subdesenvolvidas - Sociedades Industrializadas - Sociedades Agrícolas - Sociedades Estratificadas Sociedades Socialistas - Sociedades Atrasadas Na História -Sociedades Nacionais - Sociedades Agrárias - Sociedades Hidráulicas - Sociedade Periférica - Sociedade Civilizadora

ECONOMIA/S

Economias Periféricas - Economia Autônoma - Economia Industrial Economias Camponesas - Economias Capitalistas - Economias Nacionais Economias Atrasadas - Economias Rurais/Artesanais - Economia LivreEmpresarial - Economia Agrícola - Economia Agrária - Economia Monetária Economia Escravista - Economia Mercantil - Economia Pastoril - Economia Mista - Economia Urbana - Economia Rural - Economia Colonial - Economia Monetária

DESENVOLVIMENTO

Desenvolvimento Econômico - Desenvolvimento Industrial Desenvolvimento Capitalista- Desenvolvimento Tardio - Desenvolvimento Capitalista Pleno - Desenvolvimento Humano - Desenvolvimento Evolutivo Desenvolvimento Acumulativo - Desenvolvimento Econômico Desenvolvimento Histórico - Desenvolvimento Cultural - Desenvolvimento Social - Desenvolvimento Sociocultural

PROCESSO/S

Processo Civilizatório - Processo de Modernização Reflexa - Processo Produtivo - Processo de Restauração Imperial - Processo de Atualização Histórica - Processo Colonial - Processo Histórico - Processo Evolutivo Processo de Aceleração Evolutiva - Processo de Sucessão Ecológica Processo Produtivo

SISTEMA/ S

Sistema Capitalista Industrial - Sistema Produtivo - Sistema Econômico Sistema Mercantil - Sistema Agrário - Sistema Capitalista - Sistema Colonial - Sistemas Bilineares De Parentesco - Sistemas Classificatórios de Parentesco - Sistema Social - Sistema Ideológico - Sistema Político -Sistema Agrícola

Tabela 11: Candidatos a termos simples e expressões fixas e semifixas extraídos do subcorpus principal da obra OPC em língua portuguesa

\section{SOCIEDADE/ S}

Sociedade Parasitária - Sociedade Nascente - Sociedade Brasileira Sociedades Tribais Autônomas - Sociedade Tribal - Sociedade Cabocla Sociedade Colonial - Sociedade Agrária - Sociedade Sertaneja - Sociedade Solidária - Sociedade Subalterna - Sociedade Democrática- Sociedade 
Serpa, T. \& Camargo, D. C. - Antropologia da civilização: um estudo da tradução para o inglês de termos simples, expressões fixas e semifixas recorrentes em duas obras de Darcy Ribeiro

\begin{abstract}
Multiétnica - Sociedade Igualitária - Sociedades Nacionais ECONOMIA/S

Economia Pastoril - Economia Mercantil - Economia De Subsistência Economia Agrária - Economia Extrativista -Economia Comunitária Economia Agrícola - Economia Granjeira - Economia Familiar - Economia Artesanal - Economia Cafeeira - Economia Açucareira - Economia Solidária Economia Caipira - Economia Colonial - Economia Monocultora DESENVOLVIMENTO
\end{abstract}

Desenvolvimento Regional - Desenvolvimento Industrial - Desenvolvimento Autônomo

PROCESSO/S

Processo Civilizatório - Processo Produtivo - Processo De Gestão Étnica Processos Políticos - Processo de Atualização Histórica - Processo Extrativista - Processo Deculturativo

SISTEMA/S

Sistema Pastoril - Sistema Senhorial - Sistema Produtivo - Sistema Mercantil -Sistema Fundiário - Sistema De Parceria - Sistema Latifundiário Primitivo Sistema Econômico - Sistema de Coivara - Sistema de Colonato - Sistema Agrário-Mercantil - Sistema Granjeiro - Sistema Socioeconômico

Tabela 12: Candidatos a termos simples e expressões fixas e semifixas extraídos do subcorpus principal da obra OPB em língua portuguesa

Verificou-se que algumas expressões fixas e semifixas estão presentes nos subcorpora de ambas as obras, revelando, novamente, o desenvolvimento da teoria proposta pelo autor e a inter-relação entre as hipóteses apresentadas na primeira e na última obra da subárea em estudo. A seguir, apresenta-se a Tabela 13 com as expressões coocorrentes em ambas as obras e as respectivas traduções:

\begin{tabular}{|c|c|c|}
\hline $\begin{array}{l}\text { Expressões fixas e } \\
\text { semifixas } \\
\text { coocorrentes nas } \\
\text { obras do corpus de } \\
\text { estudo em língua } \\
\text { portuguesa }\end{array}$ & $\begin{array}{l}\text { Expressões fixas e semifixas } \\
\text { em língua inglesa na } \\
\text { tradução The Civilizational } \\
\text { Process }\end{array}$ & $\begin{array}{l}\text { Expressões fixas e } \\
\text { semifixas em língua } \\
\text { inglesa na tradução } \\
\text { The Brazilian People }\end{array}$ \\
\hline Sociedade Subalterna & Subordinate Society & Subordinate Society \\
\hline Sociedade Agrária & Agricultural Society & Agrarian Society \\
\hline $\begin{array}{l}\text { Sociedade } \\
\text { Estratificada }\end{array}$ & Society Stratified & Stratified Society \\
\hline Sociedade Nacional & National Society & National Society \\
\hline Economia Nacional & National Economy & National Economy \\
\hline Economia Agrícola & Agricultural Economy & Agricultural Economy \\
\hline Economia Agrária & Agricultural Economy & Agrarian Economy \\
\hline Economia Mercantil & Mercantile Economy & Mercantile Economy \\
\hline Economia Colonial & Colonial Economy & Colonial Economy \\
\hline
\end{tabular}


Serpa, T. \& Camargo, D. C. - Antropologia da civilização: um estudo da tradução para o inglês de termos simples, expressões fixas e semifixas recorrentes em duas obras de Darcy Ribeiro

\begin{tabular}{l|l|l}
\hline $\begin{array}{l}\text { Desenvolvimento } \\
\text { Industrial }\end{array}$ & Industrial Development & Industrial Development \\
\hline Processo Civilizatório & Civilizational Process & Civilizing Process \\
\hline Processo Produtivo & Productive Process & Productive Process \\
\hline Sistema Capitalista & Capitalist System & Capitalistic System \\
\hline Sistema Produtivo & Productive System & Productive System \\
\hline Sistema Mercantil & Mercantile System & Mercantile System \\
\hline Sistema Econômico & Economic System & Economic System \\
\hline Sistema Colonial & Colonial System & Colonial System \\
\hline
\end{tabular}

Tabela 13: Lista de expressões fixas e semifixas coocorrentes em OPC e OPB que apresentam variações na forma lexical dos adjetivos no corpus dos TMs

Os dados demonstram uma pequena variação no uso dos adjetivos agriculturale agrarian; civilizationale civilizing; e capitaliste capitalistic. Dessa forma, com o objetivo de confirmar o uso real de alguns deles, foi realizada uma busca a sites da internet, procurando encontrar a ocorrência de sua utilização, além dos limites de nossos corpora. Observou-se que as expressões que manifestaram alterações em ambas as obras apresentam na web as seguintes ocorrências: agricultural society (16.600.000), agrarian society (465.000), civilizational process (42.900.000), civilizing process (153.000), capitalist system (1.560.000) e capitalistic system (189.000). Notou-se que as traduções de Betty J. Meggers apresentam maior ocorrência em textos de língua inglesa na rede que as escolhas lexicais propostas por Gregory Rabassa. Entretanto, a maioria das expressões apresentou regularidade e padronização concernentes ao emprego nas Ciências Sociais e nas suas subáreas.

Com base nesses resultados, foi verificado se as palavras-chave a partir dos corpora comparáveis de textos originalmente escritos em português (TOPs) e de textos originalmente escritos em inglês (TOIs) coincidiam com as palavras-chave dos TFs e dos TMs e quais eram os termos e as expressões que também estavam presentes nesses corpora.

Dessa maneira, notou-se que a subárea não apresentou no corpus comparável em português todos os termos simples que haviam sido levantados 
Serpa, T. \& Camargo, D. C. - Antropologia da civilização: um estudo da tradução para o inglês de termos simples, expressões fixas e semifixas recorrentes em duas obras de Darcy Ribeiro

nos subcorpora de estudo em língua portuguesa. Além disso, foi verificado se as escolhas lexicais da tradutora Betty J. Meggers poderiam fornecer diferentes opções de tradução na língua inglesa para os termos e as expressões fixas e semifixas de Antropologia da Civilização em relação às estratégias utilizadas por Gregory Rabassa no processo tradutório da mesma subárea. Apresenta-se, a seguir, a Tabela 14 com os termos simples coocorrentes de maior chavicidade em ambas as obras e suas respectivas traduções por Meggers e Rabassa.

\begin{tabular}{l|l|l}
\hline $\begin{array}{l}\text { Termos simples } \\
\text { coocorrentes no par } \\
\text { de obras em língua } \\
\text { portuguesa }\end{array}$ & $\begin{array}{l}\text { Termos simples na tradução } \\
\text { The Civilizational Process }\end{array}$ & $\begin{array}{l}\text { Termos SIMPLES na tradução } \\
\text { The Brazilian People }\end{array}$ \\
\hline Adorno/s & Ornament/s & Adornment/s \\
\hline Agregado/s & Retainer/s & $\begin{array}{l}\text { Hired hands } \\
\text { Sharecroppers } \\
\text { Workers } \\
\text { Household servants }\end{array}$ \\
\hline Chefe & Head & Chief \\
\hline Cidadania & Citizenship & Citizenry \\
\hline Clientelismo & Patronage System & $\begin{array}{l}\text { Brazen service } \\
\text { Favoritism }\end{array}$ \\
\hline Convívio & Conviviality & $\begin{array}{l}\text { Group Living } \\
\text { Companionship } \\
\text { Communal Live } \\
\text { Living }\end{array}$ \\
\hline Culto & & $\begin{array}{l}\text { Cult } \\
\text { Worship } \\
\text { Ritual }\end{array}$ \\
\hline Divindade & & Divinity \\
\hline Escambo & Rite & Barter \\
\hline Negros & & Blacks \\
\hline
\end{tabular}

Tabela 14: Termos simples de maior chavicidade coocorrentes nas obras do corpus de TFs e variações nas traduções no corpus de TMs

No âmbito das expressões fixas e semifixas também tem-se a oportunidade de verificar a variação lexical na tradução. Apresenta-se, a seguir, a Tabela 15 com alguns dos exemplos nas duas obras: 
Serpa, T. \& Camargo, D. C. - Antropologia da civilização: um estudo da tradução para o inglês de termos simples, expressões fixas e semifixas recorrentes em duas obras de Darcy Ribeiro

\begin{tabular}{l|l|l}
\hline $\begin{array}{l}\text { Expressões fixas e } \\
\text { semifixas coocorrentes } \\
\text { no par de obras em } \\
\text { língua portuguesa }\end{array}$ & $\begin{array}{l}\text { Expressões fixas } \\
\text { semifixas na tradução The } \\
\text { Civilizational Process }\end{array}$ & $\begin{array}{l}\text { Expressões fixas e semifixas } \\
\text { na tradução The Brazilian } \\
\text { People }\end{array}$ \\
\hline $\begin{array}{l}\text { Aldeia Indígena } \\
\text { Diferenciada }\end{array}$ & $\begin{array}{l}\text { Undifferentiated } \\
\text { Horticultural Village }\end{array}$ & $\begin{array}{l}\text { Undifferentiated Agricultural } \\
\text { Village }\end{array}$ \\
\hline Atualização Histórica & Historical Incorporation & $\begin{array}{l}\text { Historic Updating } \\
\text { Historical Modernization }\end{array}$ \\
\hline Cidades Urbanizadas & Cities & Towns \\
\hline Concessão de Terras & Concession of Land & Awarding of Land Grants \\
\hline Condição Humana & Condition of Mankind & Human Condition \\
\hline Condição Social & Social Condition & Social Status \\
\hline Condição Tribal & Tribal Condition & Tribal Affiliation \\
\hline Convívio Social & Community Spirit & Social Companionship \\
\hline $\begin{array}{l}\text { Escravização } \\
\text { Indígena }\end{array}$ & $\begin{array}{l}\text { Enslavement of the } \\
\text { Indigenous Population }\end{array}$ & Enslavement of Natives \\
\hline Espoliação Colonial & Colonial Exploration & Colonial Exploitation \\
\hline
\end{tabular}

Tabela 15: Expressões fixas e semifixas de maior chavicidade coocorrentes nas obras do corpus de TFs e variações nas traduções no corpus de TMs

Embora os TMs apresentem possíveis traduções que foram confirmadas, em sua maioria, no corpus comparável de língua inglesa, muitos termos e expressões da subárea de Antropologia da Civilização ocorrentes no corpus de estudo não foram confirmados no corpus de TOls, devido ao seu limite de extensão. Dessa forma, realizou-se uma busca a sites da internet, procurando mostrar que os termos e as expressões em inglês que compõem as opções de tradução de Meggers e Rabassa fazem parte do uso real dos falantes, atestando o trabalho desses profissionais e apresentando a utilização além das fronteiras do corpus comparável.

No caso dos termos simples, apresenta-se a Tabela 16 contendo alguns dos principais termos do corpus de estudo, que não ocorrem nos corpora comparáveis, e suas respectivas traduções com o número de ocorrências de uso na web.

\begin{tabular}{ll|lll|l}
\hline Termos simples de & Termos simples de & Frequência de ocorrência \\
\hline
\end{tabular}


Serpa, T. \& Camargo, D. C. - Antropologia da civilização: um estudo da tradução para o inglês de termos simples, expressões fixas e semifixas recorrentes em duas obras de Darcy Ribeiro

\begin{tabular}{l|l|r}
\hline $\begin{array}{l}\text { Antropologia } \\
\text { Civilização nos TFs }\end{array}$ & $\begin{array}{l}\text { Antropologia da Civilização } \\
\text { nos TMs }\end{array}$ & $\begin{array}{l}\text { dos termos simples em } \\
\text { inglês, na web }\end{array}$ \\
\hline Açucocracia & Sugar Regime & 66.000 \\
\hline Amansadores & Trainers & 32.200 .000 \\
\hline Antitropicalismo & Anti-tropicalism & 79 \\
\hline Arranchamento & Shack Dwellers & 11.500 \\
\hline Balateiro & Balata-Gum Gatherer & 1 \\
\hline Biscateiro & Odd-J ob Worker & 91.500 \\
& Biscuit Seller & 1.490 \\
\hline Corvéia & Unpaid Work & 3.100 .000 \\
\hline Feitor & Foreman & 17.200 .000 \\
& Overseer & 13.400 .000 \\
\hline Feudalização & Feudalization & 57.000 \\
\hline Muleiro & Muletter & 1.560 \\
\hline
\end{tabular}

Tabela 16: Termos simples ocorrentes nos TFs e respectivas traduções nos TMs com o número de frequência na web

Com relação às expressões fixas e semifixas, uma análise semelhante foi realizada. A seguir, apresenta-se a Tabela 17 com exemplos de expressões fixas e semifixas e o grau de frequência de ocorrência na internet.

\begin{tabular}{|c|c|c|}
\hline $\begin{array}{l}\text { Expressões fixas e } \\
\text { semifixas de Antropologia } \\
\text { da Civilização nos TFs }\end{array}$ & $\begin{array}{l}\text { Expressões fixas e semifixas } \\
\text { de Antropologia da Civilização } \\
\text { nos TMs }\end{array}$ & $\begin{array}{lr}\text { Frequência } & \text { de } \\
\text { ocorrência } & \text { das } \\
\text { expressões fixas e } \\
\text { semifixas em inglês, na } \\
\text { web }\end{array}$ \\
\hline Abrasileiramento Cultural & Cultural Brazilianization & 8.140 \\
\hline Ação Aculturativa & AcculturativeAction & 1 \\
\hline Cerimonial Antropofágico & Anthropophagous Ceremony & 4 \\
\hline Cooperação Inter-Comunal & LinesofCooperation & 44.300 \\
\hline $\begin{array}{l}\text { Hierarquia } \quad \text { Guerreiro- } \\
\text { Sacerdotal }\end{array}$ & Warrior-PriestlyHierarchy & 1 \\
\hline J ustiçador Divino & SeekerofDivine J ustice & Não há ocorrências \\
\hline Lágrimas de Devoção & TearsofDevotion & 30.700 \\
\hline Oligarquia Cafeeira & CoffeeOligarchy & 4.430 \\
\hline População Desindianizada & De-indianizedPopulation & 3 \\
\hline $\begin{array}{lll}\text { Sociedade } & \text { Fundada } & \text { no } \\
\text { Parentesco } & & \\
\end{array}$ & SocietyBasedonKinship & 22.700 \\
\hline
\end{tabular}

Tabela 17: Expressões fixas e semifixas ocorrentes nos TFs e respectivas traduções nos TMs com o número de frequência na web

Entre os exemplos, notou-se que, em sua maioria, as traduções mostraram que os correspondentes foram escolhidos apropriadamente, 
Serpa, T. \& Camargo, D. C. - Antropologia da civilização: um estudo da tradução para o inglês de termos simples, expressões fixas e semifixas recorrentes em duas obras de Darcy Ribeiro

adequando-se ao uso pelos especialistas em Antropologia Social e Cultural de países de língua inglesa.

Também, foi observado que, quanto às questões relacionadas às opções de tradução adotadas por Meggers e Rabassa, é importante considerar, a princípio, a formação sociocultural envolvida no processo de constituição dos TMs em diferentes períodos históricos e sob a influência de diferentes sociedades e culturas.

Sabemos que Betty J. Meggers foi uma renomada arqueóloga americana, membro do Instituto Smithsonian e da Associação Antropológica. A escolha de Ribeiro pela tradução de Meggers deveu-se ao destaque de seus trabalhos enquanto pesquisadora acerca da adaptação humana na floresta tropical e da expansão dos povos civilizados pelos territórios de mata nativa latinoamericanos.

Depois de 27 anos de pesquisa e mais quatro livros produzidos na subárea de Antropologia da Civilização, o antropólogo brasileiro apresentou, no ano de 1995, suas considerações finais acerca da constituição da identidade nacional na obra 0 povo brasileiro: a formação e o sentido do Brasil. Neste caso, a versão em língua inglesa ficou a cargo do renomado tradutor e pesquisador Gregory Rabassa, especialista em Estudos Culturais. 0 trabalho foi concluído no ano de 2000, sem ter sido revisado e comentado por Darcy Ribeiro, que faleceu em fevereiro de 1997.

Ao contrário de Meggers, o tradutor optou por manter a estrutura linguística do texto de Ribeiro, revelando a explicitação dos elementos culturais brasileiros por meio da escolha de termos diferentes para expressar um mesmo conceito presente na sociedade nacional, por exemplo, a ideia de "agregado" que é traduzida por hired hands, sharecropper, workers e household servants. Observou-se que Rabassa constrói, ao longo do TM, uma imagem dos fatores geográficos, folclóricos e comunais dos grupos brasileiros, 
Serpa, T. \& Camargo, D. C. - Antropologia da civilização: um estudo da tradução para o inglês de termos simples, expressões fixas e semifixas recorrentes em duas obras de Darcy Ribeiro

a qual vai formulando-se de modo gradual no imaginário do público leitor de língua inglesa.

O estudioso concluiu que a Sociologia e a Antropologia de Darcy Ribeiro são importantes para reconhecer o Brasil como um país autônomo em sua produção científica no ramo das Ciências Sociais, auxiliando a mudar as concepções preconceituosas e dominadoras impostas pela visão eurocêntrica.

A tradução enquanto ato social e o TM como produto das relações humanas apresentam os elementos linguísticos como importantes fatores de construção do imaginário ideológico brasileiro para os leitores de língua inglesa. Ao se descrever as opções adotadas por Meggers e Rabassa para a tradução de termos e expressões recorrentes nas obras que traduziram, considera-se muito mais que a terminologia antropológica; analisa-se valores sociais envolvidos na produção textual de Ribeiro e na interpretação dos tradutores que reescrevem as ideologias de acordo com seus comportamentos comuns.

No que concerne ao uso de termos e expressões referentes ao contexto geral da estrutura e da formação das sociedades, os tradutores compartilham de condutas semelhantes que conduzem ao comportamento recorrente da tradução literal e das transposições, principalmente na descrição de atividades relacionadas a processos produtivos, relações comerciais e trocas monetárias. Pode-se citar, neste ínterim, os seguintes exemplos: "sistema econômico" $\rightarrow$ economic system; "sistema colonial" $\rightarrow$ colonial system; "economia mercantil" $\rightarrow$ mercantile economy; "sociedade subordinada" $\rightarrow$ subordinate society; "sociedade nacional" $\rightarrow$ national society.

Quanto aos brasileirismos terminológicos, nota-se que Rabassa faz de suas escolhas lexicais uma maneira de explicar, ao longo do processo tradutório, os elementos brasileiros, alternando as possibilidades de representação da LM e construindo passo a passo a compreensão do ideológico nacional, como, por exemplo, ao traduzir "escravaria" ora por slaves ora por 
Serpa, T. \& Camargo, D. C. - Antropologia da civilização: um estudo da tradução para o inglês de termos simples, expressões fixas e semifixas recorrentes em duas obras de Darcy Ribeiro

slave groups; "arraial" por settlement, camp, encampment, town, hamlet e gathering. Meggers, por sua vez, tende a realizar omissões de trechos do TF e a utilizar um mesmo vocábulo como forma de tradução para diferentes termos, por exemplo, people como correspondente para "pessoas", "povo", "gentes" e "gentio".

As relações entre os grupos sociais e as etnias também constituem caráter relevante nas obras de Ribeiro, considerando que o autor elabora uma teoria de assimilação das diferentes raças no Brasil como resultado para a formação de um povo novo. Com isso, os TMs refletem a postura adotada pelos tradutores ao conceituarem a posição social dos indivíduos por meio das escolhas lexicais que representam os grupos raciais. Essa caracterização fica bastante evidente nas opções de Meggers e Rabassa para o termo "negro".

Na tradução de 0 processo civilizatório, a arqueóloga utiliza o vocábulo inglês negro nos contextos em que o autor procura salientar os elementos constitutivos da racialidade, revelando, com isso, uma ideologia ainda relacionada ao conceito de sub-raça de nariz achatado, lábios grossos e cabelos enrolados, ou seja, as depreciações físicas e os preconceitos ficam marcados na opção lexical da tradutora. Contudo, a tradução de 0 povo brasileiro expõe a visão de Rabassa como conhecedor do universo cultural brasileiro e desvenda uma postura menos racista para o termo "negro", o qual passa a ser traduzido por black. O tradutor considera no prefácio de sua obra O negro na ficção brasileira: meio século de história literária (1965), que o Brasil situa-se entre as nações do mundo em que o modelo de relações raciais está livre de preconceito. Considera que, embora o governo brasileiro tenha demorado a colocar fim ao regime escravocrata, a razão principal da extensão do processo de escravidão deveu-se ao fato de que em comparação com outros países, no Brasil, os negros eram tratados com certa benevolência.

Ao empreender seu estudo sobre o Brasil, Rabassa observou o problema de encontrar um critério que determine quem é negro. Mostrando-nos que a 
Serpa, T. \& Camargo, D. C. - Antropologia da civilização: um estudo da tradução para o inglês de termos simples, expressões fixas e semifixas recorrentes em duas obras de Darcy Ribeiro

definição corrente nos Estados Unidos, que geralmente considera como negro qualquer um que tenha uma proporção de sangue africano, é bem diferente da adotada no Brasil, onde se faz a distinção entre o negro e o mulato. Rabassa afirma que no Brasil o termo negro só se aplica a pessoas que são aparentemente de ascendência africana predominante, enquanto que é mulata uma pessoa aproximadamente meio negra, meio branca. 0 autor ainda salienta que se um homem é de ascendência predominantemente europeia, um pouco de sangue negro não impede que seja incluído entre os brancos.

A partir dos exemplos apresentados, verificou-se que o trabalho dos tradutores revela um avanço na tendência de permitir a introdução de suas identidades ao contexto da produção dos TFs, considerando ainda as diferenças de sentido implícitas na própria linguagem. Notou-seque o processo tradutório mostra-se mais próximo das áreas de especialidade conhecidas pela arqueóloga, havendo um apagamento de características culturais e mesmo terminológicas no texto de Meggers, ao passo que Rabassa parece refletir sobre as opções lexicais que se apresentam em língua inglesa, recorrendo a textos de outra natureza, como a produção literária nacional, para realizar uma pesquisa de adequação cultural.

\section{Considerações finais}

Pôde-se verificar que o software WordSmith Tools, por meio de suas ferramentas, facilita consideravelmente a análise de grande quantidade de dados, obtidos de maneira muito mais rápida e exata do que manualmente. $\mathrm{A}$ consulta ao corpus de apoio é essencial para estudos desta natureza. Alguns termos e expressões levantados nos corpora principais apresentam possibilidades de diferentes correspondentes em língua inglesa, como por 
Serpa, T. \& Camargo, D. C. - Antropologia da civilização: um estudo da tradução para o inglês de termos simples, expressões fixas e semifixas recorrentes em duas obras de Darcy Ribeiro

exemplo, no caso do termo "vilarejo", que apresentou três possibilidades de correspondência: village (utilizada por Meggers e Rabassa), hamlet e settlement (utilizados apenas por Rabassa). As diversas opções dos tradutores apontam variações de uso nas escolhas lexicais, evidenciando, possivelmente, tentativas de apresentar ao público alvo a versatilidade da sociedade brasileira e, assim, desenhar, de maneira mais ampla, o contexto em que eles representam as diferentes facetas da cultura e da língua brasileiras.

Com relação a aproximações observadas entre os corpora de estudo de TFs e TMs, pôde-se notar que a maioria dos termos e expressões científicos levantados encontra correspondência de uso em língua inglesa e também está presente nos corpora comparáveis como, porexemplo, em "alienação" $\rightarrow$ alienation, "comunidade" $\rightarrow$ comunitye "violência" $\rightarrow$ violence. Por outro lado, há vários termos e expressões relacionados à cultura brasileira que não encontram correspondência nos corpora comparáveis escritos por autores de língua portuguesa e de língua inglesa.Ocorre, com isso, um processo de intensa variação linguística na escolha dos tradutores, como, por exemplo,em: "seringueiro" $\rightarrow$ tapper/rubber worker; "sertanista" $\rightarrow$ sertão scout/man of sertão superior/ expeditionaty; "sertão" $\rightarrow$ sertão/backland; "vagabundagem" $\rightarrow$ vagrancy/ vagaboundage; "vaquejada" $\rightarrow$ roundup/ cowmen.

Devido ao fato de boa parte dos termos e das expressões analisadas não constarem em dicionários especializados, a busca por correspondentes pode trazer dificuldades ao tradutor que procure encontrar expressões adequadas para retratar a sociedade brasileira, da melhor maneira possível, para o leitor da língua e cultura meta.

Não existe uma definição de sociedade que seja única e aceita de modo geral, pois cada grupo humano organiza-se de maneiras distintas e vê o mundo sob diferentes perspectivas. De maneira geral, os estudiosos das Ciências Sociais procuram estabelecer uma totalidade das relações sociais entre as 
Serpa, T. \& Camargo, D. C. - Antropologia da civilização: um estudo da tradução para o inglês de termos simples, expressões fixas e semifixas recorrentes em duas obras de Darcy Ribeiro

criaturas humanas, e a terminologia concernente ao panorama geral dos conhecimentos socioculturais torna-se, de certa forma, padrão. A alternância na escolha de termos fica mais evidente em elementos que são marcados socialmente por valores folclóricos e representações de atos, atores e lugares culturalmente apresentados.

Dessa forma, diante dos resultados obtidos, espera-se que este estudo possa oferecer uma contribuição para os Estudos da Tradução Baseados em Corpus e para a Linguística de Corpus. Espera-se também que os dados aqui apresentados possam fornecer subsídios a professores, pesquisadores, tradutores, alunos de tradução, bem como profissionais da área de Ciências Sociais, no sentido de promover a conscientização acerca das diferenças socioculturais contidas no léxico de especialidade e, também, de oferecer material de suporte para futuras traduções e pesquisas na área antropológica e social.

\section{Referências bibliográficas e Bibliografia consultada}

Textos selecionados para a compilação dos corpora

\section{Corpus principal (paralelo) de Antropologia da Civilização}

RIBEIRO, D. O processo Civilizatório. Rio de Janeiro: Editora Civilização Brasileira S. A., 1968.

.The Civilizational Process. Translated by Betty M. Meggers. Washington: SmithsonianInstitution Press, 1968.

- O povo brasileiro: a formação e o sentido do Brasil. São Paulo: Companhia das Letras, 1995.

. The Brazilian People: formation and meaning of Brazil, Translated by Gregory Rabassa. Gainesville: University Press of Florida, 2000. 
Serpa, T. \& Camargo, D. C. - Antropologia da civilização: um estudo da tradução para o inglês de termos simples, expressões fixas e semifixas recorrentes em duas obras de Darcy Ribeiro

\section{Referências bibliográficas}

BarRos, L. A. Curso básico de Terminologia. São Paulo: EDUSP, 2004.

BAKER, M. In other words: a coursebook on translation. London and New York: Routledge, 1992.

Corpus linguistics and translation studies: implications and applications. In: BAKER, M.; FRANCIS, G.; TOGNINI-BONELLI, E. (Org.). Text and technology: in honour of John Sinclair. Amsterdam: John Benjamins. 1993, p. 233-250.

. Corpora in translation studies: an overview and some suggestions for future research. Target, Amsterdam, v. 7, n. 2. 1995, p. 223-243.

- Corpus-based translation studies: the challenges that lie ahead. In: SOMERS, HERALD. (Ed). Terminology, LSP and translation studies in language engineering: in honour of J uan C. Sager.Amsterdam: J ohn Benjamins, 1996, p. 177-186.

Linguística e estudos culturais: paradigmas complementares ou antagônicos nos estudos da tradução? In: MARTINS, M. A. P. (Org). Tradução e multidisciplinaridade. Rio de J aneiro: Lucena, 1999, p. 1534.

- Towards a Methodology for investigation the style of literary translation. Target, Amsterdam, V. 12, n. 2. 2000, p. 241-266.

Berber Sardinha, T. Lingüística de Corpus. Barueri, SP: Manole, 2004.

CAMARGO, D. C. DE. Padrões de estilo de tradutores: um estudo de semelhanças e diferenças em corpora de traduções literárias, especializadas e juramentadas.512 f. Tese (Livre-docência em Tradução) - Instituto de Biociências, Letras e Ciências Exatas - Unesp, Universidade Estadual Paulista, São J osé do Rio Preto, 2005.

Metodologia de pesquisa em tradução e linguística de corpus. São Paulo: Cultura Acadêmica/São José do Rio Preto: Laboratório Editorial(Coleção Brochuras, v. 1), 2007.

CoelHo, O. Léxico, Ideologia e a Historiografia Linguística do Século das Identidades. RevistaLetras, n.61, p.153-166, Editora UFPR. Curitiba, 2003.

EVEn-ZOHAR, I. The position of translated literature within the literary polisystem. In: Holmes, J.; Lambert, J.; Van Den Broeck, R. (Ed.). Literature and translation. Leuven, 1978, p. 83-100, [Versão revisada 
Serpa, T. \& Camargo, D. C. - Antropologia da civilização: um estudo da tradução para o inglês de termos simples, expressões fixas e semifixas recorrentes em duas obras de Darcy Ribeiro

em VenUtI, L. (Ed.). The translation studies reader. London/ New York: Routledge, 2000, p.198-211]

FAULSTICH, E. Duas questões em discussão: o que são brasileirismos nos dicionários de Língua Portuguesa? Existem brasileirismo terminológicos? In: Jornada sobre "Variación Geolectal i Terminologia"Red Panlatina de Terminologia Realiter/IULAterm/Institut Universitari de Linguística Aplicada. Barcelona, Espanha, 24 de novembro de 2004.

Heim, M. H.; Tymowski, A. Guideliness for the Translation of Social Science Texts . Nova lorque: American Council of Learned Societies, 2006.

KRIEger, M. G.; FinAtTI, M. J. B. Introdução à Terminologia: teoria e prática. São Paulo: Editora Contexto, 2004.

Pathak, L.P. Sociological Concepts and Terminology. New Delhi: Anmol Publications PVT. Ltda., 1998.

RABASSA, G. O negro na ficção brasileira: meio século de história literária. Trad. de Ana Maria Martins. Rio de J aneiro: Tempo Brasileiro, 1965. . If this be Treason: Translation and its Dyscontents - a memoir. New York: New Direction Publishing Corporation, 2005.

SINCLAIR, J. Corpus, concordance and collocation. Oxford: OxfordUniversity Press, 1991.

Tognini-Bonelul, E. Corpus linguistics at work. Amsterdã/Atlanta: John Benjamins, 2001.

TOURY, G. The nature and role of norms in literary translation. In: HOLMES, J.; Lambert, J.; Van Den Broeck, R. (Ed.). Literature and translation. Leuven, 1978, p117-127.[Versão revisada em VenUtI, L. (Ed.).The translation studies reader. London/New York: Routledge, 2000, p. 192-198]. 